\title{
PENURUNAN METODE NICKALLS DAN PENERAPANNYA PADA PENYELESAIAN PERSAMAAN KUBIK
}

\author{
MISNAWATI \\ Program Studi Matematika, \\ Fakultas Matematika dan Ilmu Pengetahuan Alam, Universitas Andalas, \\ Kampus UNAND Limau Manis Padang, Indonesia, \\ email : misnawati.ua@gmail.com
}

\begin{abstract}
Abstrak. Pada paper akan dibahas penurunan metode Nickalls dan implementasi perhitungannya pada MATLAB dalam menyelesaikan persamaan kubik. Metode ini merupakan modifikasi dari metode Cardan dengan terlebih dahulu mendefinisikan parameterparameter tertentu yang dapat mendeskripsikan solusi yang diperoleh dengan bentuk geometri dari kurva fungsi kubik. Penyelesaian persamaan kubik dengan metode ini menghasilkan akar-akar bernilai riil yang dibagi atas tiga kasus berdasarkan hubungan parameter-parameter didefinisikan.
\end{abstract}

Kata Kunci: Cardan, Titik belok, Kecekungan

\section{Pendahuluan}

Persamaan kubik sudah dikenal sejak zaman Mesir dan Yunani kuno. Persamaan tersebut muncul dari masalah-masalah yang mereka hadapi pada pengukuran tanah. Beberapa matematikawan Yunani yang berperan dalam pengembangan metode penyelesaian persamaan kubik adalah Hippocrates, Men-aechmus, dan Diophantus. Metode-metode yang mereka gagas kemudian diperbaiki oleh matematikawan Arab seperti Al-Mahani, Abu Jafar Al-Hazin dan Ummar Khayam. Perkembangan selanjutnya tentang metode penyelesaian persamaan kubik berasal dari matematikawan Eropa seperti Leonardo Pisa, Lucas Pacioli, Scipo Ferro dan Nicolo Brescia.

Metode yang lebih populer untuk masalah kubik ini dikembangkan oleh Tartaglia pada tahun 1541 yang menemukan solusi umum untuk persamaan $x^{3}+p x^{2}=q$ dengan melakukan transformasi sedemikian sehingga diperoleh bentuk $x^{3}+m x=n$. Metode ini sebetulnya sudah digagas sebelumnya oleh Cardan yang dipublikasikan di Ars Magna. Pada paper ini akan dibahas metode alternatif lain dari penyelesaian persamaan kubik yang merupakan modifikasi dari metode Cardan. Metode alternatif ini digagas oleh Nickalls [2].

\section{Parameter-Parameter pada Fungsi Kubik}

Perhatikan kembali bentuk umum fungsi polinomial berderajat $n$ berikut:

$$
f(x)=a_{n} x^{n}+a_{n-1} x^{n-1}+\cdots+a_{0}, a_{n} \neq 0,
$$


dengan $n$ adalah bilangan bulat positif dan $a_{i}$ adalah koefisien polinomial dengan $i=0,1,2, \cdots, n$. Misalkan $x_{1}, x_{2}, \cdots, x_{n}$ adalah akar-akar dari persamaan $f(x)=0$ maka $x_{1}+x_{2}+x_{3}+\cdots+x_{n}=-\frac{a_{n-1}}{a_{n}}$.

Sekarang misalkan $N\left(x_{N}, y_{N}\right)$ adalah suatu titik yang terdapat pada kurva polinomial $f(x)$ sedemikian sehingga dengan menggeser sumbu-x sejauh $x_{N}$, yaitu menggunakan transformasi $z=x-x_{N}$, membuat jumlah akar-akar dari polinomial baru $f(z)$ sama dengan nol, yaitu $z_{1}+z_{2}+\cdots+z_{n}=0$. Dari hubungan ini berlaku

$$
x_{N}=-\frac{a_{n-1}}{n a_{n}} .
$$

Dari persamaan (2.2) diperoleh bahwa jika $f(x)$ merupakan fungsi kubik dengan bentuk umum

$$
f(x)=a x^{3}+b x^{2}+c x+d,
$$

maka $x_{N}=-\frac{b}{3 a}$. Dengan mensubstitusi $x=z+x_{N}$ ke persamaan (2.3), diperoleh

$$
f(z)=a z^{3}+\left(c-\frac{b^{2}}{3 a}\right) z-\frac{c b}{3 a}+d+\frac{2 b^{3}}{27 a^{2}},
$$

yang merupakan fungsi kubik tereduksi. Perhatikan bahwa $f^{\prime \prime}(x)>0$ dipenuhi oleh $x<x_{N}$, dan $f^{\prime \prime}(x)<0$ dipenuhi oleh $x>x_{N}$ dengan $x_{N}=-\frac{b}{3 a}$. Dari kenyataan ini, maka $N$ adalah titik belok pada kurva fungsi kubik (2.3).

Selanjutnya misalkan $\delta, \lambda, h$ didefinisikan sebagai parameter-parameter jarak. Dengan menyelesaikan persamaan $f^{\prime}(x)=0$, dimana $f(x)$ adalah fungsi kubik (2.3), diperoleh titik ekstrim pada

$$
x_{1,2}=x_{N} \pm \frac{1}{3 a} \sqrt{b^{2}-3 a c}
$$

Tulis $\delta=\frac{1}{3 a} \sqrt{b^{2}-3 a c}$, sehingga berlaku $\delta^{2}=\frac{b^{2}-3 a c}{9 a^{2}}$ dan $c=\frac{b^{2}+9 a^{2} \delta^{2}}{3 a}$. Selanjutnya, nilai $h$ diberikan oleh

$$
h=-3 a x_{N}^{2} \delta-3 a x_{N} \delta^{2}-a \delta^{3}-b \delta^{2}-c \delta .
$$

Dengan mensubstitusikan $x_{N}=-\frac{b}{3 a}$ dan $c=\frac{b^{2}+9 a^{2} \delta^{2}}{3 a}$ ke persamaan (2.4), diperoleh

$$
h=2 a \delta^{3}
$$

Selanjutnya, nilai $\lambda$ dapat ditentukan dari hubungan

$$
a x_{N}^{3}+(3 a \lambda+b) x_{N}^{2}+\left(3 a \lambda^{2}+2 b \lambda+c\right) x_{N}+b \lambda^{2}+c \lambda+d=0
$$

Dengan mensubstitusikan $x_{N}=-\frac{b}{3 a}$ ke persamaan (2.6), diperoleh solusi

$$
\lambda=0, \pm \frac{\sqrt{3 b^{2}-9 a c}}{3 a} .
$$

Karena $\lambda$ haruslah positif dan dengan menggunakan hubungan $\delta=\frac{1}{3 a} \sqrt{b^{2}-3 a c}$, maka

$$
\lambda=\sqrt{3} \delta
$$


Dari hasil di atas, dapat disimpulkan bahwa bentuk fungsi kubik $f(x)$ dikarakterisasi oleh parameter $\delta$, yaitu mempunyai nilai maksimum dan minimum yang berbeda (untuk $\delta^{2}>0$ ), atau berimpit di $N$ (untuk $\delta^{2}=0$ ), atau tidak ada titik ekstrim (untuk $\delta^{2}<0$ ). Lebih lanjut,

$$
\frac{a \delta \lambda^{2}}{h}=\frac{a \delta 3 \delta^{2}}{2 a \delta^{3}}=\frac{3}{2},
$$

yang menunjukkan bahwa $\frac{a \delta \lambda^{2}}{h}$ bernilai konstan pada sebarang fungsi kubik $f(x)=$ $a x^{3}+b x^{2}+c x+d$.

\section{Pendekatan Nickalls}

Pandang kembali persamaan kubik

$$
f(x)=a x^{3}+b x^{2}+c x+d=0 .
$$

Misalkan akar-akar dari persamaan (3.1) adalah $\alpha, \beta$, dan $\gamma$. Dengan menggunakan substitusi $x=x_{N}+z$, diperoleh persamaan kubik tereduksi

$$
a z^{3}-3 a \delta^{2} z+y_{N}=0,
$$

dimana $\delta=\frac{1}{3 a} \sqrt{b^{2}-3 a c}$ dan $y_{N}=f\left(x_{N}\right)=a x_{N}^{3}+b x_{N}^{2}+c x_{N}+d$. Jelas bahwa akar-akar dari persamaan kubik (3.2) adalah $\alpha-x_{N}, \beta-x_{N}$, dan $\gamma-x_{N}$.

Misalkan $z=p+q$ adalah solusi dari persamaan (3.2). Dengan menggunakan substitusi

$$
p q=\delta^{2} \quad \text { dan } \quad p^{3}+q^{3}=-\frac{y_{N}}{a},
$$

maka persamaan (3.2) dapat ditulis dalam bentuk

$$
(p+q)^{3}-3 p q(p+q)-\left(p^{3}+q^{3}\right)=0 .
$$

Selanjutnya dari persamaan (3.3) diperoleh hubungan

$$
p^{3}+\frac{\delta^{6}}{p^{3}}=-\frac{y_{N}}{a} \Leftrightarrow a\left(p^{3}\right)^{2}+y_{N} p^{3}+a \delta^{6}=0 .
$$

Solusi persamaan (3.4) diberikan oleh

$$
p^{3}=\frac{-y_{N} \pm \sqrt{y_{N}^{2}-4 a^{2} \delta^{6}}}{2 a} .
$$

Berdasarkan persamaan (2.5) yaitu $h^{2}=4 a^{2} \delta^{6}$, maka

$$
p^{3}=\frac{1}{2 a}\left\{-y_{N} \pm \sqrt{y_{N}^{2}-h^{2}}\right\} .
$$

Akibatnya

$$
q^{3}=\frac{1}{2 a}\left\{-y_{N} \mp \sqrt{y_{N}^{2}-h^{2}}\right\} .
$$

Dari kedua persamaan terakhir, jelas bahwa solusi persamaan kubik (3.2) mempunyai satu solusi riil jika

$$
y_{N}^{2}>h^{2} .
$$


Selanjutnya karena $y_{N}^{2}-h^{2}=\left(y_{N}+h\right)\left(y_{N}-h\right)$, maka persamaan (3.5) dapat ditulis kembali dalam bentuk

$$
p^{3}=\frac{1}{2 a}\left\{-y_{N} \pm \sqrt{\left(y_{N}+h\right)\left(y_{N}-h\right)}\right\} .
$$

Jika ordinat dari titik ekstrim adalah $y_{T_{1}}$ dan $y_{T_{2}}$, maka berdasarkan Gambar 3.1.1 dapat ditulis

$$
y_{N}+h=y_{T_{1}} \operatorname{dan} y_{N}-h=y_{T_{2}} .
$$

Dengan demikian persamaan (3.6) menjadi

$$
p^{3}=\frac{1}{2 a}\left\{-y_{N} \pm \sqrt{y_{T_{1}} y_{T_{2}}}\right\} .
$$

Jika diskriminan dari persamaan kubik didefinisikan sebagai berikut :

$$
\Delta_{3}=y_{T_{1}} y_{T_{2}}=y_{N}^{2}-h^{2},
$$

maka nilai diskriminan $\Delta_{3}$ ini membedakan akar-akar persamaan kubik atas tiga kasus berikut:

(1) Kasus $y_{N}^{2}>h^{2}$, dimana persamaan kubik memiliki 1 akar riil

(2) Kasus $y_{N}^{2}=h^{2}$, dimana persamaan kubik memiliki 3 akar riil (dengan 2 atau 3 akar yang sama)

(3) Kasus $y_{N}^{2}<h^{2}$, dimana persamaan kubik memiliki 3 akar riil yang berbeda

Berikut penjelasan masing-masing kasus.

3.0.1. Kasus $y_{N}^{2}>h^{2}$

Jelas bahwa pada kasus ini hanya terdapat 1 akar riil. Karena diskriminan $\Delta_{3}$ bernilai positif, maka nilai akar riil $\alpha$ diberikan oleh

$$
\alpha=x_{N}+z=x_{N}+p+q,
$$

dimana nilai $p$ diperoleh dari persamaan (3.6), yaitu

$$
p=\sqrt[3]{\frac{1}{2 a}\left(-y_{N} \pm \sqrt{y_{N}^{2}-h^{2}}\right)},
$$

sedangkan nilai $q$ diperoleh dari persamaan (3.2.11), yaitu

$$
q=\sqrt[3]{\frac{1}{2 a}\left\{-y_{N} \mp \sqrt{y_{N}^{2}-h^{2}}\right\}} .
$$

Jadi nilai $\alpha$ adalah

$$
\alpha=x_{N}+\sqrt[3]{\frac{1}{2 a}\left(-y_{N}+\sqrt{y_{N}^{2}-h^{2}}\right)}+\sqrt[3]{\frac{1}{2 a}\left(-y_{N}-\sqrt{y_{N}^{2}-h^{2}}\right)} .
$$


3.0.2. Kasus $y_{N}^{2}=h^{2}$

Jika $h \neq 0$, maka terdapat dua subkasus :

(i) Subkasus $y_{N}=h$.

Pada subkasus ini diperoleh

$$
p^{3}=\frac{-h}{2 a}
$$

dan

$$
q^{3}=-\frac{h}{2 a} .
$$

Jadi

$$
z=p+q=2 \sqrt[3]{\frac{-h}{2 a}}=2 \sqrt[3]{\frac{-2 a \delta^{3}}{2 a}}=-2 \delta .
$$

Misalkan $-2 \delta$ adalah untuk $z_{3}$. Nilai $z_{1}$ dan $z_{2}$ dapat ditentukan dari sifat penjumlahan dan perkalian akar-akar dari persamaan (3.2), yaitu

$$
z_{1}+z_{2}+z_{3}=0
$$

dan

$$
z_{1} z_{2} z_{3}=-\frac{y_{N}}{a} .
$$

Karena $z_{1}=-2 \delta$ dan $y_{N}=h=2 a \delta^{3}$, maka

$$
z_{1}+z_{2}=2 \delta \text { dan } z_{1} z_{2}=\frac{-2 a \delta^{3}}{-2 a \delta}=\delta^{2},
$$

yang memberikan solusi

$$
z_{1,2}=\delta
$$

(ii) Subkasus $y_{N}=-h$.

Pada subkasus ini diperoleh

$$
p^{3}=\frac{h}{2 a}
$$

dan

$$
q^{3}=\frac{h}{2 a} .
$$

Jadi

$$
z=p+q=2 \sqrt[3]{\frac{h}{2 a}}=2 \sqrt[3]{\frac{2 a \delta^{3}}{2 a}}=2 \delta .
$$

Misalkan $2 \delta$ adalah untuk $z_{3}$. Dengan melakukan cara yang serupa pada subkasus sebelumnya diperoleh $z_{1,2}=-\delta$.

Dengan demikian untuk kasus $y_{N}^{2}=h^{2}$ diperoleh:

(i) $x_{1,2}=x_{N}+\delta$ dan $x_{3}=x_{N}-2 \delta\left(\right.$ untuk $\left.y_{N}=h\right)$,

(ii) $x_{1,2}=x_{N}-\delta$ dan $x_{3}=x_{N}-2 \delta\left(\right.$ untuk $\left.y_{N}=-h\right)$.

Selanjutnya jika $y_{N}=h=0$, maka $\delta=0$, sehingga pada kasus ini terdapat tiga akar kembar di $x=x_{N}$. 
3.0.3. Kasus $y_{N}^{2}<h^{2}$

Pada kasus ini terdapat tiga akar riil yang berbeda. Namun, solusi tersebut memuat akar pangkat tiga dari bilangan kompleks, sehingga untuk menyelesaikan persamaan kubik tereduksi pada persamaan (3.2) akan lebih mudah menggunakan substitusi $z=2 \delta \cos \bar{\theta}$ ke persamaan (3.2), sehingga diperoleh

$$
\begin{gathered}
a(2 \delta \cos \bar{\theta})^{3}-3 a \delta^{2}(2 \delta \cos \bar{\theta})+y_{N}=0 \\
\Leftrightarrow 2 a \delta^{3}\left(4 \cos ^{3} \bar{\theta}-3 \cos \bar{\theta}\right)+y_{N}=0 .
\end{gathered}
$$

Karena $h=2 a \delta^{3}$ dan $\cos 3 \bar{\theta}=4 \cos ^{3} \bar{\theta}-3 \cos \bar{\theta}$, maka persamaan (3.7) menghasilkan

$$
\cos 3 \bar{\theta}=-\frac{y_{N}}{h}
$$

sehingga diperoleh

$$
\Leftrightarrow \bar{\theta}=\theta+\frac{2 k}{3} \pi, k=0,1,2
$$

dimana $\theta=\frac{\arccos \left(\frac{-y_{N}}{h}\right)}{3}$. Jadi akar-akar $\alpha, \beta, \gamma$ diberikan oleh:

$$
\begin{aligned}
& \alpha=x_{N}+2 \delta \cos \theta, \\
& \beta=x_{N}+2 \delta \cos (2 \pi / 3+\theta), \\
& \gamma=x_{N}+2 \delta \cos (4 \pi / 3+\theta) .
\end{aligned}
$$

Posisi akar-akar tersebut ditunjukkan pada Gambar 3.1.4 dalam lingkaran dengan jari-jari $2 \delta$ dan berpusat $N$. Selanjutnya perhatikan juga bahwa dari persamaan (3.8) diperoleh hubungan

$$
-1<\frac{y_{N}}{h}<1
$$

\section{Algoritma Metode Nickalls}

Berikut ini adalah algoritma metode Nickalls.

Masukan : $a, b, c, d$ (koefisien persamaan kubik).

Keluaran : $\alpha, \beta, \gamma$ (akar-akar riil persamaan kubik).

Langkah-langkah:

1. $x_{N}:=-b /(3 a)$

2. $y_{N}:=a x_{N}^{3}+b x_{N}^{2}+c x_{N}+d$;

3. $\delta:=\frac{1}{3 a} \sqrt{b^{2}-3 a c}$;

4. $h:=2 a \delta^{3}$;

5. Jika $y_{N}^{2}-h^{2}>0$ maka

$$
\begin{aligned}
\alpha & :=x_{N}+\sqrt[3]{\frac{1}{2 a}\left(-y_{N}+\sqrt{y_{N}^{2}-h^{2}}\right)}+\sqrt[3]{\frac{1}{2 a}\left(-y_{N}-\sqrt{y_{N}^{2}-h^{2}}\right)} \\
\beta & :=x_{N}+2 \delta \cos (2 \pi / 3+\theta) \\
\gamma & :=x_{N}+2 \delta \cos (4 \pi / 3+\theta)
\end{aligned}
$$

Jika tidak maka 
jika $y_{N}^{2}-h^{2}<0$ maka

$$
\begin{aligned}
\theta & :=\left[\arccos \left(-y_{N} / h\right)\right] / 3 ; \\
\alpha & :=x_{N}+2 \delta \cos \theta ; \\
\beta & :=x_{N}+2 \delta \cos (2 \pi / 3+\theta) ; \\
\gamma & :=x_{N}+2 \delta \cos (4 \pi / 3+\theta) ;
\end{aligned}
$$

jika tidak maka

$$
\text { jika } y_{N}=h \text { maka }
$$

$$
\begin{aligned}
& \alpha:=x_{N}+\delta \\
& \beta:=x_{N}+\delta \\
& \gamma:=x_{N}-2 \delta
\end{aligned}
$$

jika tidak maka

$$
\begin{aligned}
\alpha & :=x_{N}-\delta \\
\beta & :=x_{N}-\delta \\
\gamma & :=x_{N}+2 \delta
\end{aligned}
$$

\section{Pemrograman dan Hasil}

Sintaks pemrograman metode Nickalls pada MATLAB yang diberikan dalam bentuk program fungsi

$$
>\mathrm{x}=\text { nickallskubik }(\mathrm{a}, \mathrm{b}, \mathrm{c}, \mathrm{d})
$$

dimana $\{a, b, c, d\}$ adalah koefisien-koefisien persamaan kubik (3.1) dan akarakarnya diberikan oleh array $\mathrm{x}$. Berikut diberikan contoh penyelesaian tiga persamaan kubik yang merepresentasikan masing-masing kasus.

(i) Untuk persamaan kubik

$$
x^{3}-3 x^{2}+x-1=0,
$$

diperoleh $y_{N}^{2}-h^{2}>0$. Pada MATLAB, akar persamaan kubik (5.1) dapat dihitung dengan memanggil perintah berikut:

$$
>\mathrm{x}=\text { nickallskubik }(1,-3,1,-1) \text {. }
$$

maka diperoleh akar $x=2.7693$ (dua akar lainnya bernilai kompleks).

(ii) Untuk persamaan kubik

$$
x^{3}-7 x^{2}+14 x-8=0,
$$

diperoleh $y_{N}^{2}-h^{2}<0$. Pada MATLAB, akar persamaan kubik (5.2) dapat dihitung dengan memanggil perintah berikut:

$$
\text { > } \mathrm{x}=\text { nickallskubik }(1,-7,14,-8)
$$

maka diperoleh akar-akar $x_{1}=4, x_{2}=1, x_{3}=2$. 
(iii) Untuk persamaan kubik

$$
x^{3}-3 x+2=0
$$

diperoleh $y_{N}^{2}=h^{2}$. Pada MATLAB, akar persamaan kubik (5.3) dapat dihitung dengan memanggil perintah berikut:

$$
>\mathrm{x}=\text { nickallskubik }(1,0,-3,2)
$$

maka diperoleh akar-akar $x_{1,2}=1$ dan $x_{2}=-2$

\section{Ucapan Terima kasih}

Penulis mengucapkan terima kasih kepada Bapak Dr. Mahdhivan Syafwan, Ibu Riri Lestari, M.Si, Bapak Prof. Dr. Syafrizal Sy, Bapak Efendi, M.Si, dan Bapak Narwen, M.Si yang telah memberikan masukan dan saran sehingga paper ini dapat diselesaikan dengan baik.

\section{Daftar Pustaka}

[1] Katz, Victor J. 2012. A History of Mathematics. 2th edition. Pearson, New York.

[2] Nickalls, R. W. D. 1993. A new approach to solving the cubic: Cardan's solution revealed. The Mathematical Gazette 77 : 354 - 359

[3] Varberg, D., Purcell, E.J., dan Rigdon, S.E. 2006. Calculus, 9th edition. Pearson, New York.

[4] Burnside, W. S dan Panton, A. W. 1881. Theory of Equations. Dublin University Press, Dublin. 